\title{
Globalización y medios de comunicación ¿Hacia la aldea global?
}

Mónica Gendreau

Universidad Iberoamericana-Golfo Centro

EL SURGIMIENTO de los medios de comunicación masiva es un rasgo fundamental constitutivo de las sociedades contemporáneas, entretejido con el desarrollo del capitalismo industrial y con el surgimiento del estado-nación moderno. Es un proceso que a su vez ha transformado profundamente las formas en que circulan las formas simbólicas en las sociedades modernas.

Con la aparición en la vida social de los medios de comunicación, el proceso de transmisión cultural se vuelve crecientemente mediado por un grupo de instituciones comprometidas con la mercantilización y circulación extensiva de formas simbólicas. En las últimas décadas estas instituciones se han integrado en conglomerados a gran escala, y la circulación de formas simbólicas se ha tornado cada vez más global (Shiller, 1993). Por otra parte, el desarrollo de nuevas tecnologías de comunicación ha seguido y facilitado estas tendencias y, al mismo tiempo, ha marcado el comienzo de una significativa y nueva marcha en la historia de las modalidades de la transmisión cultural (Thompson, 1990).

Actualmente en México vivimos profundas transformaciones en la economía, la política, la cultura y la sociedad en general. La inserción del país en el Tratado de Libre Comercio es un hecho más que viene a reforzar dichas transformaciones, y su influencia se hará sentir también en la llegada de grandes corporaciones en el área de las comunicaciones que necesariamente habrán de transformar la oferta comunicacional y el acceso a nuevas tecnologías de comunicación por parte de la población. Mc Luhan (1989) emplea el término de "aldea global" para enfatizar el hecho de la simultaneidad y amplitud de la experiencia televisiva en un ámbito mundial ampliado. Sin embargo, el concepto mismo de "globalización" oculta una serie de procesos que ocurren en diversas esferas y a escalas también diferenciadas, por lo que es necesario identificar en qué medida o de qué manera 
Globalización y medios de comunicación ¿Hacia ...

se comparten ciertos elementos 0 , por el contrario, de qué manera este proceso pretendidamente "homogeneizador" se encuentra dialécticamente acompañado por otro que, contrariamente, acentúa la diferencia y los elementos ideosincráticos de la comunicación. Es decir que, a este proceso de globalización o "mundialización" de la economía y de los "mass media" le acompaña otro de diferenciación arraigada en las particularidades culturales y sociales de las regiones y localidades menores.

De aquí nuestro interés por iniciar el estudio, en este laboratorio social, de la influencia de cstos cambios en la reestructuración de los usos y apropiación de los contenidos culturales massmediados en la vida cotidiana de dos sectores diferenciados: uno urbano y otro rural en el centro de México. Estos se presentan como dos escenarios diversos regidos por lógicas sociales y culturales no sólo diversas, sino aún contrapuestas (Bonfill, 1990).

El presente trabajo vierte la discusión y resultados preliminares de un proyecto de investigación en proceso, que deberá ser enriquecido y ampliado. Se ha dividido en tres partes. En la primera se presenta el contexto social y relevancia de esta investigación desde la perspectiva teórica del estudio del cambio cultural e identitario. En segundo lugar, se hace el planteamiento metodológico que abarca el proyecto global, señalando la parte que que se reporta en el presente artículo. Por último, en la tercera sección se presentan resultados preliminares que nos permitirán plantear hipótesis consistentes en torno a la integración/resistencia de los productos culturales ofrecidos por los medios masivos de comunicación, avanzando algunas conclusiones ilustrativas.

La investigación profundiza el estudio de las relaciones entre los medios de comunicación -tanto radio, TV como las llamadas "nuevas tecnologías": videocasetera, sistemas satelitales de comunicación, redes computacionales, entre otros- y los usuarios de diferentes contextos socioculturales, cuyas prácticas cotidianas determinan estrategias diversas en su uso y apropiación. En este sentido, los objetivos del estudio son:

1. Describir los patrones de uso (integración/resistencia) de las nuevas tecnologías de comunicación (NTC) y la manera en que éstas transforman significativamente las relaciones interpersonales en el seno de la familia (en las relaciones padres/hijos y de género hombre/mujer) en dos contextos sociales diferentes (urbano/rural o moderno/tradicional).

2. Mostrar la manera en que la presencia de las NTC intervienen en la conformación de las representaciones sociales en los individuos según la edad, el sexo y el origen sociocultural y socioeconómico de sus familias. Asímismo, descubrir las diferencias 
o semejanzas entre las representaciones propuestas por los medios y aquéllas propias de la familia en cuanto a los roles, normas o valores que rigen su vida cotidiana.

3. Descubrir la posible relación entre la adquisición y uso de NTC y la conformación de una cosmovisión de la vida "moderna" y urbana.

En el siguiente apartado se presentarán los conceptos necesarios para estudiar el uso de medios a partir de variables socioculturales que puedan ser fácilmente operacionables y permitan guiar el trabajo de campo y la recuperación de la información sobre este fenómeno.

\section{Problemática del "uso" de medios}

Hasta ahora, la investigación de la comunicación desde las ciencias sociales que estudian a las audiencias de televisión han oscilado entre dos polos. Por un lado, se encuentran perspectivas que otorgan un poder importante a los mensajes (poder de los contenidos, de la retórica o el texto) transmitidos a través de los medios masivos de comunicación, han tenido como fuente originaria la "Teoría de la Aguja Hipodérmica" (Bullet Theory, Srhamm, 1971). En el otro extremo, se conforma la perspectiva teórica que ha intentado poner a la luz la autonomía relativa del receptor frente a estos mensajes, gracias al papel selectivo de la audiencia quien realiza una recepción diferenciada de los mensajes, mejor conocida como "Usos y Gratificaciones" (Halloran, 1970; Blumer, Katz, 1974).

Sin embargo, estas dos vertientes de la "Communication Research" norteamericana carecen de una perspectiva sociológica o cultural en su apreciación del proceso comunicativo. De ahí que nos interese partir de una veta de investigación que surge de la tradición inglesa de estudios de la cultura iniciada por Clifford Geertz(1985) y transferida al ámbito de los medios de comunicación principalmente por Sturart Hall (1982) y David Morley $(1986,1992)$. Estos presentan un modelo comunicacional centrado en la codificación/decodificación que permite avanzar en el estudio de los procesos de comunicación en su contexto sociocultural. Retoman de la teoría de los efectos la noción de que la comunicación de masas es una actividad estructurada, en la cual las instituciones que producen mensajes tienen el poder de establecer agendas y definir los asuntos. Sin embargo, en contra de esta visión simplista, afirman que la comunicación no se da de manera puntual, individual o aislada, sino que los medios de comunicación masiva al establecer agendas, proveen a su vez de categorías culturales y marcos de referencia dentro de los cuales los miembros de una cultura pueden operar (Thompson, 1992). 
Esta perspectiva incorpora también de la teoría de Usos y Gratificaciones el papel activo de la audiencia, que permite resignificar o reactualizar aquellos signos y símbolos que los medios proveen. Sin embargo, se trata de una teoría que, dentro de un paradigma normativo e interpretativo, se preocupa por estudiar las formas en las cuales las respuestas e interpretaciones se encuentran estructuradas y formadas más allá de las psicologías individuales (Moscovici, 1986, 1989). El centro de la cuestión está en que siempre nos encontramos negociando con signos y símbolos cuyo significado depende de los términos de las referencias obtenidas a través de códigos compartidos por la audiencia y, en cierta medida, por los productores del mensaje (Grize, 1990).

El modelo de codificación/decodificación permite proveer una sintesis de las distintas aproximaciones a la comunicación que ofrecen perspectivas diversas como la teoría de la comunicación, la semiología, la sociología y la psicología social, para construir un modelo de circuito de comunicación desde la manera que opera en su contexto social. Parte del argumento de que uno debe prcguntarse no por el significado de un texto, sino por las condiciones de una práctica, es decir, por examinar los fundamentos de la comunicación, pero examinando dichos fundamentos como un fenómeno social y cultural (Bourdieu, 1980, 1985).

En América Latina encontramos un grupo representativo de investigaciones en torno a los usos sociales y familiares de algunas programaciones (Orozco Gómez, 1990, 1992, 1994), y específicamente de las telenovelas (Alfaro, 1988; Barrios, 1988; Bautista, Covarnubias y Uribe, 1991; González, 1988; Reyes Matta, 1986).

\subsection{La Esquematización}

A partir de la crítica del modelo comunicacional de Shannon y Weaver, Grize (1990) propone un modelo de comunicación operativo en el que interviene la esquematización como parte del proceso comunicativo y como expresión de la naturaleza dialógica del lenguaje. En otras palabras, parte del hecho de que el diálogo es la forma más "natural" del lenguaje. Sin embargo, el estudio de la "situación" en la que éste ocurre permite aprehenderlo como un proceso complejo debido al conjunto de símbolos que entran en juego en una situación real de diálogo.

En el siguiente diagrama se presenta el modelo del proceso comunicacional en el que el locutor $A$ construye una representación discursiva de aquéllo de que habla o trata (T), que es por definición una esquematización. Esto se realiza dentro de una situación de diálogo (real o potencial) que supone siempre un interlocutor $B$ que reconstruye la 
esquematización que le es propuesta. Aunque no es este el lugar para poder profundizar, conviene hacer las precisiones mínimas que Grize establece y que permiten que este modelo sea aplicado para el análisis de la comunicación de los medios masivos en un contexto social y cultural específico.

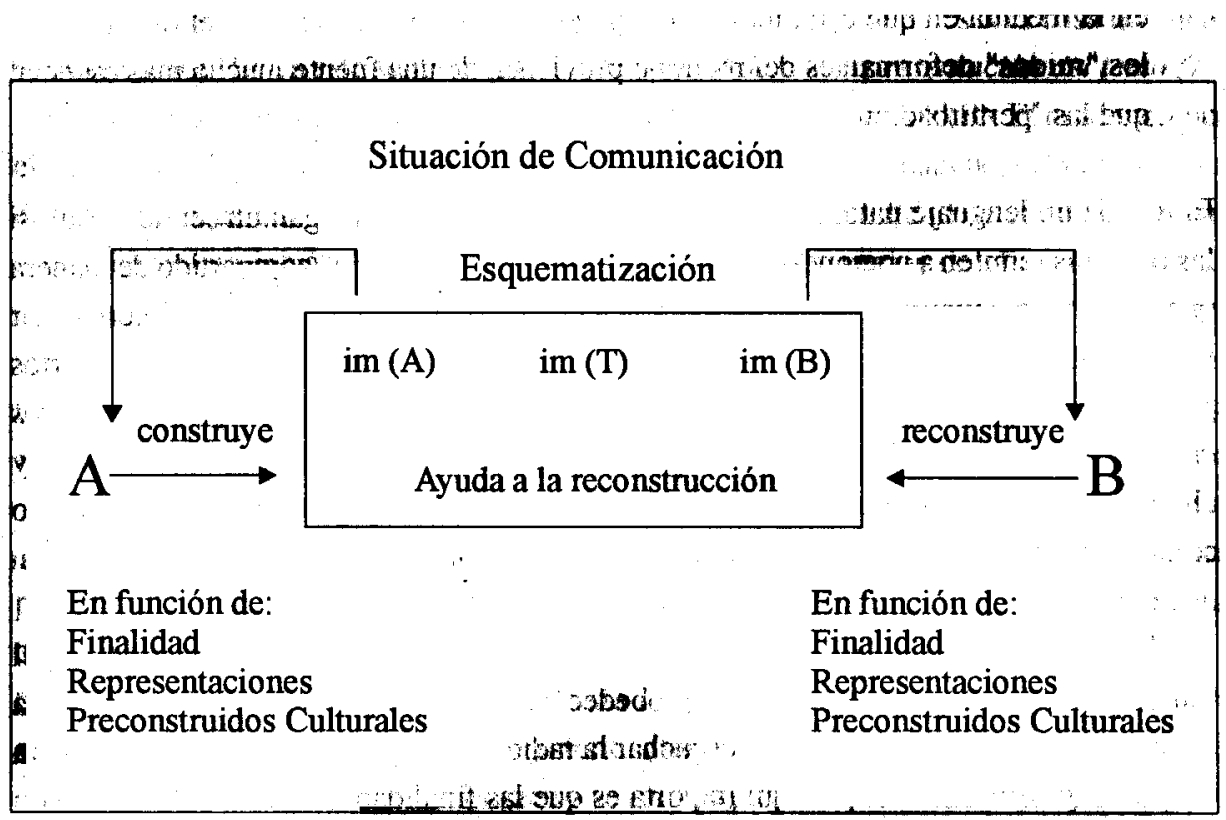

Fuente: Grize (1990: 29)

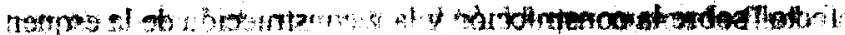

En la lectura de este diagrama, el autor propone las siguientes precisiones:

1. A y B no designan individuos concretos. Son lugares en el seno de un marco teórico, en el entendido de que, en cada caso de aplicación, estos lugares son ocupados por "verdaderos" sujetos con todo aquéllo que podrían contener de constricciones psicológicas y sociales. El lugar de B puede por tanto ser ocupada no por un individuo, sino por un grupo de sujetos por lo que se trataría no de un receptor, sino de una audiencia.

2. El esquema representa aquéllo que sucede cuando A tiene la palabra. En un diálogo verdadero (situación dialogal), cada participante tomará alternativamente el lugar de A y el de B de manera que pueden haber estrategias complejas de toma de la palabra. 
3. Si el esquema de Shannon reposa sobre la imagen de transferencia de 'bits de información', podemos decir metafóricamente que ésta se inspira en la inducción, en la resonancia, en sentido psíquico del término [...] Sin embargo, la reconstrucción de una esquematización no será jamas verdaderamente isomorfa a su construcción en la medida en que cada individuo real es único. Vemos aquí que el problema de los "ruidos" deformantes del mensaje provienen de una fuente mucho más esencial que las 'perturbaciones' del canal (Grize, 1990: 29-30).

El uso de un lenguaje natural hace que los signos empleados tengan un sentido. Aún si las palabras remiten a nociones, cada una de ellas posee un "nudo" compartido de manera que permite la comunicación. Por ejemplo, al hablar de gato o de perro, mi interlocutor comprende a qué me refiero. Lo interesante es que el lenguaje natural remite a ciertos preconstruidos que son de naturaleza social tanto como cultural. Los preconstruidos culturales son los que dan lugar a las llamadas "cadenas de expectación" (expentancy chains) y a los prejuicios. Ambos elementos desempeñan un papel central en el proceso comunicativo y, sin embargo, han sido "soslayados" por los análisis de la comunicación que consideran que ésta se da de manera casi transparente.

Asimismo, las finalidades (sean cognitivas o afectivas) o propósitos juegan un papel fundamental en la comunicación, pues obedecen a alguna razón o motivo ya sea para hablar o para escuchar -uno puede escuchar la radio o leer "para matar el tiempo" o para estar bien informado. Lo que aquí importa es que las finalidades de A o de B tienen un "efecto" sobre la construcción y la reconstrucción de la esquematización.

Por último, Grize (1990) resalta la importancia la situación comunicacional en tanto constituyente del marco teórico de la comunicación. No se pone en duda que las circunstancias materiales sobre las cuales se produce un discurso influyen directamente en los propósitos, forma y contenido de éste. Sin embargo, siguiendo a Pecheux (1969) el autor afirma que la situación de comunicación remite tanto a las relaciones de fuerza como de sentido propios de la estructura social imprimiendo al discurso las características del sujeto representativo de esta relación. En ella se imprime tanto su situación socio-económica como su posición (ideológica) en la estructura social. Grize añade una precisión, al señalar que Pierre Bourdieu (1980), en este sentido, parece reducir toda la eficacia de la palabra al lugar que ocupa el locutor de manera que "la autoridad del lenguaje viene de fuera". Sin embargo, afirma nuestro autor, hay que admitir que la relación es dialéctica entre las prácticas discursivas y sus condiciones socio-culturales de realización. Es así que el Grize permite considerar de manera más precisa la eficacia 
del proceso comunicativo, que no le es derivada por ciertas condiciones externas, sino que se manifiestan como parte integrante de éste.

Por último, las representaciones sociales se refienen a cierto tipo de imágenes compartidas necesarias para que se dé la comunicación. Es evidente que para tener un discurso sobre no importa qué tema, hay que tener una idea, que no es otra cosa que una representación. Es en este sentido que el locutor $A$ tiene una representación del tema $(T)$ $y$ de su interlocutor $(B)$-en el diagrama se expresa reprA (T) y reprA (B). El orador como el que escucha tienen representaciones y el discurso propone imágenes. Hablar de las representaciones que A se hace de B no es más que una comodidad de expresión. Uno no se representa jamás a una persona, sino sólo algunos aspectos de ella: sus saberes, valores, habilidades. Y lo mismo sucede con el tema, ya que A (el autor de un discurso) se forma una representación del tema y de sí mismo. Hay por tanto tres familias de representaciones repr $A(A)$, repr $A(B)$ y repr $A(T)$ que además podrían hacerse complejas reprA (A,B), reprA (B,T) y reprA (A,T). Esto mismo sucede con el interlocutor $B$.

Resulta indispensable aclarar que toda esquematización remite tanto a un proceso creador (que da lugar a una esquematización), como a un resultado (una imagen). En palabras del autor, "la esquematización es una simplificación de la realidad, una forma de organizar el material verbal, es decir, los signos (las palabras) que remiten a preconstuidos culturales" (Grize, 1990: 35). De esta manera la esquematización es creadora de sentido en tanto que se hace frente al interlocutor y se destina a éste. Cabe señalar que, sea que se hable o escriba, todo discurso se realiza frente a un interlocutor y se espera que tenga algún impacto en éste -es el efecto del "feed back" que marca la flecha de retorno en el diagrama.

Por lo tanto, la comunicación no es un proceso "transparente" ni unívoco, parte de un contexto mínimo de acuerdo, requiere de la actitud espontánea de todos frente a una esquematización previa y a la esquematización como resultado, como presentación de un microuniverso que comparte el preconstruido cultural subyacente. Esquematizar un aspecto de la realidad (representarlo) ficticiamente o no, es un acto semiótico, implica "dar a ver". De ahí que este esquema habla de imágenes. Los sujetos situados en A y B tienen representaciones, pero la esquematización propone imágenes: de A, B y T. "En resumen, una esquematización es un signo en tres sentidos primordiales: remite a aquéllo que es esquematizado, es puesta en su lugary, además, remite a los universos de creadores y de interlocutores." (Nattiez, 1975:58 citado por Grize, 1990).

Una esquematización no esta hecha más que de imágenes. LLeva en si las marcas que ayudan a su reconstrucción. Marie-Jeanne Borel distingue tres planos a los cuales remite: 
el cognitivo, el argumentativo y el retórico..." (Citado por Grize, 1990:38-39) A los que añadiríamos, siendo congruentes con esta presentación, el social y el cultural.

Es a partir de esta concepción amplia del proceso comunicativo que se desarrolla nuestra investigación, la cual pretende describir los comportamientos y esquematizaciones ligados a las diversas propuestas de los medios (y específicamente de algunas de las nuevas tecnologías: cable, antena parabólica, televisión con señal restringida o video) dentro de las condiciones habituales de su utilización, es decir, en el seno de la familia (Lull, 1988; Morley, 1986 y 1992; Lindlof,1987), para dar cuenta del conjunto de comportamientos e interacciones entre los miembros de la familia y el uso y contenido de los medios de comunicación (Proulx,1992; Houston, Donnerstein, et. al. 1992). Por ello será necesario estudiar el proceso comunicativo desde el punto de vista no del emisor (A) sino del interlocutor (B) tratando de desentrañar el tipo de representaciones que éste se hace tanto del emisor (A) como del contenido o tematización ( $T$ ) en dos contextos (uno urbano y otro rural) ajenos a los de la producción de la comunicación.

El hecho de que las nuevas tecnologías de comunicación -y aún gran parte de la programación radiofónica o televisiva-presentan determinadas esquematizaciones de la realidad pertenecientes a contextos culturales diversos a los latinoamericanos, parten de una representación de su audiencia repr $A(B)$ y de la tematización repr $A(T)$ que seguramente difiere de aquéllas generadas en el contexto de estudio. A partir de esta concepción del proceso comunicacional, podemos afirmar que no puede darse una "simple transmisión" de contenidos, sin embargo, el objetivo de este estudio es descubrir si en las representaciones de los interlocutores $\operatorname{repr} \mathrm{B}(\mathrm{A})$ y $\operatorname{reprB}(\mathrm{T})$ para el caso familias urbanas y rurales en México existen diferencias considerables o empieza a generarse un contexto comunicativo cada vez más compartido y no-diferenciado.

El segundo caso, el de contar con representaciones compartidas y comunes tanto en la programación de los medios como en sus receptores, corresponde a la idea McLuhanianna de "Aldea Global" en la que los referentes son compartidos por todos aquéllos que "ven" un mismo acontecimiento por televisión. Sin embargo, queremos señalar, nuestro marco teórico nos llevaría a proponer lo contrario. Es decir, que independientemente de lo amplia y culturalmente diferenciada que pueda ser una audiencia, ésta interpretará (por decir lo menos) de manera diversa esos mismos contenidos, ya que el contexto socio cultural del que parte es diferente, si no es que contrapuesto o contrario. Ello habrá de ser estudiado.

Nuestro interés por estudiar el contexto urbano y el rural está en el hecho de que, consideramos que en las áreas urbanas podriamos encontrar una mejor "comprensión" de 
los contenidos mediáticos dadas las similitudes con los contextos de producción -podríamos esperar que la vida diaria de una familia en el contexto de la ciudad de Puebla fuese semejante a la de otras zonas urbanas norteamericanas-mientras que en las localidades rurales existiría una mayor "distancia" o podría esperarse que las esquematizaciones correspondiesen a elementos culturales tradicionales realmente diferentes a los de producción. Pero, nuevamente, es necesario contrastar estos supuestos empíricamente.

Por último, dado que partimos de un contexto social sumamente diferenciado -en México existen poblaciones rurales tradicionales que viven en condiciones de enormes carencias frente a grupos urbanos modernos y con grandes capacidades económicaspretendemos describir las estrategias de apropiación/resistencia desarrolladas por los usuarios de distintos grupos sociales frente a estas nuevas tecnologías, para encontrar algunas consideraciones teórico/metodológicas de la relación existente entre cultura, medios de comunicación y cambio social. (Shinar, et.al. 1990). En este último punto, nos interesa explorar la existencia de alguna relación entre la supuesta "influencia" de los medios de comunicación en las representaciones de la vida "moderna" en las comunidades. Rogers (1989) ha trabajado enormemente esta línea de investigación que relaciona la transmisión de tecnologías y el cambio social. A nosotros nos parece una relación mucho más compleja y menos directa.

\subsection{Inserción de la investigación en la tradición de estudios sobre la cultura en América Latina}

El proyecto se inserta en una reciente pero rica vertiente de investigación en torno a la cultura en América Latina y, específicamente, en México. Autores como Bonfil Batalla (1985, 1990), García Canclini (1982,1985), Giménez (1987, 1993) Lomnitz-Adler (1995) han enriquecido la perspectiva etnográfica de los estudios sobre las culturas en la región. Particularmente Martín Barbero $(1987,1992)$ y Márquez de Melo (1992) han estudiado la problemática de la comunicación en medios socioculturales diversos, donde los modelos de la "communication research" norteamericanos no permitieron comprender la dimensión cultural de los procesos de comunicación.

\section{Lineamientos Metodológicos}

Si nuestro interés está en analizar las representaciones sociales en el contexto de la comunicación masiva, debemos conformar una estrategia metodológica adecuada. Para 
ello, conviene distinguir tres momentos u objetos de estudio de la comunicación masiva, para después proponer las técnicas más adecuadas para su medición.

Estos tres momentos definidos por Grize (1990) y considerados desde el ámbito de los medios masivos de comunicación son: la producción/transmisión o difusión de las formas simbólicas mediadas a través de las tecnologías de comunicación(A); la construcción/codificación de los mensajes de los medios ( $\mathrm{T}$; y la recepción/decodificación y apropiación de los mensajes masss-mediados (B). Como vimos en el punto anterior, estos son elementos de un mismo proceso que, aunque puedan ser estudiados en momentos diferentes dada la complejidad de métodos requeridos para su comprensión, ello se realizará sin perder de vista que se tratan de aspectos de un solo proceso complejo e integrado y que, por lo tanto, conservan las "huellas" de éste.

Este enfoque comprensivo de la comunicación masiva requiere de la capacidad de analizar estos tres aspectos y de mostrar cómo se interrelacionan entre sí en la producción, transmisión y recepción de las formas simbólicas mediadas por las tecnologías comunicacionales (Thompson, 1992, 1995).

En este primer trabajo iniciamos el estudio de la comunicación a partir de la recepción (B), es decir, centrándonos en las esquematizaciones diferenciadas de los mensajes ofrecidos según son generadas por los individuos pertenecientes a contextos socioeconómicos y culturales diferentes. Por ello, la metodología debe plantearse en una doble vía que compare el análisis de las representaciones propuestas por los mensajes -reprA(T) y reprA(B)- con el análisis de las recepciones diferenciadas de estos mensajes -reprB(T) y reprB(A).

En este primer acercamiento nos servirán de guía las aproximaciones etnográficas de las audiencias, tales como los trabajos de los británicos Morley $(1986,1992)$ y Silverstone (1990), y del americano Lull $(1980,1990)$. Estos se basan en un minucioso trabajo de observación de los usos de las NTC en las familias con las que pretenden captar la dinámica contradictoria entre las especificidades y los usos de la vida cotidiana de los individuosen-familia y las "generalidades impuestas" por una cultura de masas pretendidamente "omnipresente e invasora."

Haciendo eco a las recomendaciones de Jensen y Rosengreen (1990) concernientes a los diseños de investigación de audiencias, buscaremos emplear una estrategia de investigación de naturaleza comparativa (comparación de familias de diversos contextos socio económicos y culturales) combinando una aproximación sociológica convencional -que se apoya en la tradición de estudios cuantitativos concernientes a los usos, acceso a televisión y nuevas tecnologías, etc.- y una aproximación etnográfica relativamente 
nueva para el estudio de la recepción de los medios de comunicación en ambiente familiar -inspirándose en nuevas corrientes de la etnografía de la recepción. Estaremos así en posibilidades de trazar un bosquejo descriptivo y analítico, utilizando de manera complementaria datos cualitativos y cuantitativos. La complementariedad entre ambas aproximaciones parte de una lógica metodológica de triangulación donde la debilidad de una aproximación se compensa con la fuerza del otro, en la producción de descripciones sucesivas y paralelas de la realidad aprehendida de esta manera.

En un segundo momento, se precisará de un análisis de la estructura de algunos mensajes -televisivos, radiofónicos, videográficos, etc.- a partir de la teoría de las esquematizaciones sociales (Grize, 1990). Sin embargo, iniciamos el estudio de este circuito comunicativo a partir del interlocutor (B) que, en este caso, al ser colectivo, sería considerado audiencia.

\subsection{Delimitación de la Población de Estudio y Técnicas de Investigación}

Se selecionaron cuatro familias de diversos niveles socioeconómicos y ámbitos (urbano y rural). Dos familias en el ámbito urbano -en la ciudad de Puebla-y dos en área rural -en la localidad de San Jerónimo Coyula, municipio de Atlixco, Pue.' Las primeras correspondían a nivel socioeconómico medio y alto $^{2}$, ambas familias nucleares con hijos dependientes menores de 21 años, en una de ellas la madre de familia no trabajaba y en la otra ambos padres trabajaban tiempo completo. En el caso de las familias en zona rural, ambas pertenecen al nivel socioeconómico bajo, una de ellas es extensa y la otra nuclear ${ }^{3}$.

Una primera etapa consistió en la realización de una encuesta en ambas poblaciones -entre finales de 1993 y mediados de 1994-para conocer el acceso a los medios masivos y nuevas tecnologías de comunicación (NTC) así como los usos, programas, horarios y preferencias. ${ }^{4}$ De esta manera se contó con una base descriptiva y representativa de la

1 La ciudad de Puebla con cerca de dos millones de habitantes es la 4a. ciudad de la República Mexicana. San Jerónimo Coyula, por el contrario es una comunidad rural con 4,300 habitantes. Su actividad primordial es la agricultura de temporal. Se eligieron estas localidades por la cercanía con la Universidad y por el conocimiento con que contamos los investigadores de la propia región.

2 La estratificación de la población en cinco niveles socioeconómicos se realizó empleando un análisis factorial combinando variables de ingreso, servicios urbanos y educación en las distintas Areas Geoestadísticas Básicas proporcionadas por INEGI y con datos del XI Censo Nacional de Población, 1990.

3 En el apartado 3 señalamos las diferencias entre familia nuclear y extensa.

4 Se puede consultar el reporte M. Gendreau (1994) "Exposición a los Medios de Comunicación en la Ciudad de Puebla." Universidad de las Américas-Puebla. Mimeo para el caso de la zona urbana. 
realidad de los medios de comunicación en las unidades familiares urbanas y rurales, lo que nos permite establecer, de entrada, una primera fuente de diferenciación social, ya que las actividades de trabajo y descanso de familias con acceso a NTC presentan características muy particulares, no sólo por la amplitud en la selección de horarios y contenidos, sino por el ritmo e interrelaciones que les imprimen.

En la segunda etapa, destinada a obtener información relevante en torno a las representaciones sociales y dar respuesta a los objetivos planteados, se realizaron una serie de entrevistas en profundidad $-a$ todos los miembros de la familia-apoyadas en una guía de observación participante. ${ }^{5}$ Cabe mencionar que, para facilitar nuestro trabajo, la selección de las unidades familiares se hizo con base en relaciones de amistad o de parentesco con los propios investigadores ya que era fundamental contar con un ambiente de confianza que nos permitiera convivir y penetrar en su vida privada.

Tanto la guía de observación como las entrevistas buscan desentrañar si el uso de NTC y las representaciones sociales asociadas a estos mensajes coinciden o no con aquéllas propias del entorno socio cultural familiar. Estas se acompañan por la observación de las interacciones familiares y grupales generadas a partir de los medios -horarios, programación, temática, intención o propósito-destacando el papel que éstos juegan en la vida cotidiana de los diversos miembros de la unidad familiar y empleando el contexto urbano/rural, el género, la edad (en cuanto a integrantes de tres generaciones: padres/hijos/nietos), el rol familiar (padres/hijos/hermanos), la escolaridad y la ocupación (incluyendo experiencia migratoria) como variables de contrastación.

Reconocemos que aún haría falta, en una tercera etapa, el análisis de algunos mensajes de la programación para compararlos con la reelaboración (esquematizaciones) de algunos miembros familiares a través de sesiones de grupo. Sin embargo, en todo momento se busca enontrar las "huellas" del circuito de comunicación, en el sentido de no olvidar que el estudio del interlocutor (B) -en nuestro caso la recepción mediática en la familia- lleva implícita la consideración del emisor (A) y la temática (T) como lo

5 Los resultados del estudio monográfico en zona urbana se encuentran en Gendreau, M. (1995) Socio cultural change and the presence of new communication technologies within urban families in Central Mexico, Midwestem Sociological Association, Chicago, Il April, 1995 y los resultados preliminares del estudio en la zona rural han sido presentados de manera más extensa en Gendreau M. y G. Giménez (1996) Between Popocatépetl and Brooklyn... Migration and Media: Two ways of altering regional identity in Central Mexico. Paper submitted to the Intercultural and Development Division of the International Communication Association. 46th Annual Conference, Chicago, Il. May 26th 
establece el diagrama anteriormente descrito. Y este circuito debe ser comprendido en cierto contexto socio cultural.

Resumiendo, la estrategia metodológica combina elementos de las técnicas sociológicas extensivas con aquéllas técnicas provenientes de la etnometodología que busca describir los entramados sociales en que se negocia el sentido, a partir de la estructura dialógica de la comunicación en la que los actores no son concebidos meramente como "portadores de estructuras" -sean estas económicas, sociales o culturales- sino que, a través de la práctica discursiva las actualizan y generan (Giddens, 1987).

\section{Resultados preliminares: Hacia la diferenciación}

Los resultados preliminares de la investigación serán presentados en dos partes. En la primera se hablará de la presencia de los medios masivos y NTC en la ciudad de Puebla y en la localidad de San Jerónimo Coyula como parte de los resultados de una encuesta que nos permite apreciar en términos descriptivos el "uso" de los medios en ámbitos diversos, de manera que pueda realizarse una primera comparación en términos de disponibilidad de ciertos medios y tecnologías. En la segunda, se mostrará la manera en que las familias en los dos ámbitos ubican sus aparatos, el tiempo y las reglas que gobiernan la vida familiar y sus relaciones con los medios, sus programaciones preferidas y la manera en que afectan la interacción interpersonal, tratando de mostrar las maneras diversas de aproximación dependiendo de la edad, sexo y ocupación en contextos socioculturales diversos como son el campo y la ciudad.

\subsection{La ubicuidad de los medios masivos de comunicación.}

1. El Contexto Urbano. A partir de una encuesta realizada en la ciudad de Puebla a 700 familias en una muestra estratificada y aleatoria, distribuida según cuotas en función de sexo y edad, se encontró una mínima diferenciación en el acceso a medios masivos en diferentes niveles socioeconómicos (Gendreau, 1994). Uno de los resultados más interesantes fue encontrar la radio como el medio más popular. Todas las familia (97.3\%) tienen al menos un aparato receptor, y es frecuente encontrar un promedio de tres por unidad familiar. La radiograbadora es también popular $(85.4 \%)$, lo que nos permite apreciar la situación competitiva entre estos dos medios auditivos. 
Globalización y medios de comunicación ¿Hacia ...

La televisión es igualmente popular, ya que el $85.5 \%$ de las familias tienen entre uno y tres aparatos. Solamente el $3.1 \%$ reportó no contar con este aparato. La Videograbadora empiea a ser tan común como la TV, ya que el $65 \%$ de las familias afirmaron tener al menos una (31.9\% sistema Beta y $32.9 \%$ vHs). Este promedio resulta ser elevado si comparamos con el salario anual per cápita que en México es alrededor de $\$ 2,000$ dólares. Sin embargo, las Nuevas Tecnologías de Comunicación (NTC) no son tan populares, y podríamos afirmar que constituyen una fuente de diferenciación social entre la población. Solamente el $3.3 \%$ de la población cuenta con antena parabólica y $6.7 \%$ con sistema de televisión vía satélite (MVS). La instalación de cable se inicia en la ciudad de Puebla hasta 1995 por lo que no contamos todavía con información sobre su alcance.

Por su parte, aunque la prensa es el medio con la mayor trayectoria histórica en el pais, los bajos ingresos y nivel educativo, nos permiten comprender el porqué solamente el $10 \%$ de la población lee algún diario. Las revistas son más populares y, aunque no se especifica si se trata de gazetas, tiras cómicas, fotonovelas u otro tipo, la encuesta arrojó que cerca del 85.6\% afirmó leer al menos una revista al mes. Desde luego, las más leidas fueron: TV Guía y TV Novelas, lo que indirectamente relaciona esta importancia de la presencia televisiva.

En cuanto a "consumo" de medios, si bien esta información es enormemente criticable por su superficialidad, la radio se escucha diariamente en el $71.4 \%$ de los hogares. Encontramos una competencia "natural" entre ésta y la televisión, ya que la radio se escucha primordialmente en la mañana (9:00 a 12:00 hrs) en cerca del 60\%de las familias; mientras que la TV empieza a ganar atención en la tarde llegando hasta el $71 \%$ de los hogares a las 21:00 horas. La encuesta arrojó información interesante en torno a horarios, programas preferidos, etc. que no puede ser ampliado aquí. Sin embargo, cabe señalar que, a pesar de que en las familias encontramos varios aparatos de radio y TV, éstas en su mayoría (84\%) continúan escuchando radio y viendo TV en grupo. En muy contadas ocasiones -y fundamentalmente en familias de nivel socioeconómico alto- se encontró que se cncendian varios aparatos al mismo tiempo.

2. El Contexto Rural. En la población de San Jerónimo Coyula, municipio de Atlixco, Puebla, se llevó a cabo un censo sobre medios de comunicación en las cerca de 700 familias de la localidad a finales de 1995. A pesar de que la televisión tiene alrededor de 25 años de haber entrado en dicha comunidad (según las autoridades municipales), se ha extendido a más del $80 \%$ de las familias; sin embargo, el número de canales que pueden captarse son muy limitados ( 2,7 y 13 nacionales y 3 local) debido a la interferencia que 
hace el Popocatépetl. Respecto a la radio, fue introducido en la comunidad hace ya más de 40 años y encontramos al menos 1 radio en el $98 \%$ de las familias, habiendo de 2 a 3 aparatos receptores en el $\mathbf{4 5 \%}$ de éstas. Las radiograbadoras son igualmente comunes y aunque señalaron escuchar música primordialmente en español, constituyen una fuente alterna de "acompañamiento" de sus actividades.

En cuanto a las nuevas tecnologías, en la población no existe antena parabólica, ni televisión vía satélite. Son my contadas las familias que llegan a tener Videograbadora (menos del $12 \%$ ) y en la población no existen centros de renta de películas. Como era de esperarse, al no encontrarse ningún expendio de diarios o revistas y dado el elevado nivel de analfabetismo de la población, no existe una cultura de lectura de periódicos o impresos. En muy contadas ocasiones (y predominantemente los jóvenes menores de 25 años) se señaló la compra de algunas revistas (tiras cómicas y fotonovelas).

En este primer momento, al comparar el ámbito urbano y rural en cuanto a la presencia de medios masivos de comunicación, vemos que en cuanto a radio y televisión nacional no podríamos asegurar que existe una diferencia importante. Los aparatos receptores de radio y TV se encuentran casi universalmente presentes en todas las familias, sin distingo de nivel socioeconómico o ámbito urbano/rural. Sin embargo, existen diferencias sutiles pero importantes en cuanto a la sofisticación (y precio) de los mismos. Ya que los aparatos de TV y Videograbadoras más complejas (a color, con las últimas innovaciones tecnológicas de encendido a control remoto, etc.) se encuentran unicamente en los niveles socioeconómicos más altos de la zona urbana. Lo mismo sucede con los aparatos de música -incluyendo radio, grabadora y reproductora de disco compacto. Los más sofisticados y tecnológicamente avanzados, se encuentran en contadas familias. Pero el hecho es que, en la mayoría de las familias las estaciones locales son igualmente escuchadas.

Ahora bien, si nuestra investigación se quedara en este primer nivel descriptivo, difícilmente podríamos encontrar diferencias en la forma de integrar los medios de comunicación a la vida cotidiana de las poblaciones. Esto coincide claramente con las informaciones sobre ratings de programas -deportivos, telenovelas y películas- ${ }^{6}$ que son

6 Recientemente Televisa publicó los programas con mayor rating según el Instituto Brasileño de Opinión Pública (IBOP), en los que sobresalen, en los 100 primeros lugares: encuentros deportivos, telenovelas y películas. Es sorprendente que no se hayan mencionado programas informativos o de debate. Estos ratings son obtenidos como promedios ponderados en toda la población de la República Mexicana y no permiten obtener más que estos datos "duros" que sirven para cotizar el tiempo de publicidad en los distintos canales de televisión. 
Globalización y medios de comunicación $¿$ Hacia ...

los más vistos por la población en general, casi sin diferencias importantes. Sin embargo, la segunda parte de la investigación, aquélla realizada a partir de una aproximación etnográfica nos permite encontrar contrastes muy interesantes entre las diversas poblaciones, como veremos a continuación.

\subsection{Familia, medios y vida diaria: El contexto de las representaciones}

La investigación de campo pretende descubrir el lugar, tiempo y reglas que gobiernan tanto las relaciones familiares como los usos e interrelación con los medios masivos, señalando la manera sutil en que éstos intervienen (¿afectan?) la interacción cotidiana. Además es la única vía con que contamos para empezar a descubrir las diversas representaciones que se forma el receptor a partir de aquéllas propuestas por los medios.

Por ésto, resulta fundamental describir las maneras diferentes en que se emplean los medios masivos y NTC dependiendo de variables como el sexo, la edad, la ocupación, el rol al interior de la familia (padres, hijos), así como el contexto en el que dicha familia se insertaba (urbano/rural). Entretejido con estas variables, se encuentra presente la variable cultural que, aunque no puede ser "medida" directamente, nos permitirá explicar la selección y "los gustos" por cierto tipo de programación que presenta esquematizaciones más o menos coincidentes con las propias.

A través de la observación participante y la entrevista profunda a los miembros de las familias se busca describir la manera en que los programas (temáticas) presentados por los medios eran re-construidos o re-vividos en familia o en la interacción con los amigos, el trabajo o la vida social. Resulta fundamental descubrir el grado en que éstos permiten a la familia prolongar su problemática diaria hacia su localidad, ciudad o aún al país entero. Esta es una manera indirecta de conocer si los medios presentaban elementos coincidentes con su visión del mundo, con la representación social de algunas temáticas (esquematizaciones) o si, por el contrario, las temáticas eran del todo ajenas. Conocer cuál era el objetivo que los guiaba a buscar determinada programación o medio en específico. De esta manera iríamos reconstruyendo en el tejido de la vida diaria, la manera sutil pero fundamental en que los medios formaban parte de sus proyectos, pasatiempos, objetivos y metas de vida familiar o individual.

La importancia de estudiar los medios masivos en su "ambiente natural" constituido por la familia ha sido suficientemente argumentado en las secciones precedentes. Sin embargo, la estructura familiar es sumamente variable entre culturas y medios sociales. De ahí que, sea necesario precisar, en términos generales, que en la sociedad mexicana 
encontramos dos estructuras familiares. La primera, la familia extensa que aparece en su forma tradicional, como un núcleo familiar en donde varias generaciones viven bajo el mismo techo. En este sentido, la unidad familiar se compone de varias parejas y sus descendientes, que cooperan para lograr ciertos objetivos económicos (subsistencia) y sociales (asegurar el buen cuidado de los padres en la vejez, así como la continuidad de las normas y costumbres en los menores). Este tipo de familia se encuentra característicamente en ambientes tanto rurales como suburbanos, correspondiendo a culturas "tradicionales." A pesar de que este tipo de estructura extensa tendería a desaparecer con la "modernidad" y la migración hacia las grandes ciudades, aún aquí la encontramos con cierta regularidad en los niveles socioeconómicos bajos preferentemente.

La familia nuclear, más común en las zonas urbanas y en niveles socioeconómicos altos, se componen por la pareja fundamental (padre y madre) e hijos. Sin embargo, este grupo llega a indluir a algunos familiares individualmente considerados (la abuela, algún tío, etc.) que vive con la familia nuclear y que en ocasiones realiza actividades relacionadas con el cuidado de los hijos o las labores del hogar. Cabe señalar la creciente importancia que empiezan a tener las familias uniparentales (en gran medida encabezadas por mujeres) principalmente en las áreas urbanas, pero aún en algunas zonas rurales donde existe una elevada migración masculina.

Conviene precisar, por último, que el trabajo de campo se realizó, en el ámbito urbano, durante 15-20 días de 1995, mientras que, el ámbito rural requirió de un tiempo de incersión más prolongado, es decir, entre 2 y 4 meses en 1996. La duración del trabajo de campo estaba supeditado a poder responder a los diversos lineamientos de una guía de observación, combinada con otra guía de entrevista (no estructurada) que debería realizarse a todos y cada uno de los miembros de la familia. ${ }^{7}$ Dado que, como investigadores, el medio urbano nos es mucho más conocido, el trabajo se realizó sin muchos contratiempos. No así en el ámbito rural, en donde no resulta fácil introducirse en la casa y compartir con las familias.

1. El ámbito urbano. En la ciudad de Puebla -considerada la 4a. ciudad de la República Mexicana, con cerca de 1,900,000 habitantes- se eligieron dos familias nucleares con

7. Los investigadores son estudiantes del Taller de Investigación II de la licenciatura de Ciencias de la Comunicación de la Universidad de las Américas-Puebla. También se aprovechó el trabajo de tesis de Julio César Tapia Guzmản(1996) "Bacanales Cualitativas o Por qué la teoria de medios no se aplica en un medio rural" Tesis de Licenciatura en Ciencias de la Comunicación UDLA-P, así como parte de mi trabajo en un proyecto de investigación más amplio sobre medios y migración en el Valle de Atlixco. 
Globalización y medios de comunicación ¿Hacia ...

las siguientes características: parejas con hijos dependientes, menores de 21 años de edad, con acceso a medios masivos y algún otro tipo de NTC (computadora, teléfono celular, televisión restringida, etc.). Los padres de familia, originarios de la propia ciudad, con grado escolar universitario y viviendo en alguna colonia residencial.

Goodman (1983) señala que la familia es un sistema bovernado por reglas, y sus miembros por tanto se encuentran organizados de manera repetitiva y estructurada, de manera que estos patrones pueden ser analizados para descubrir los principios de la interacción familiar. Aquí encontramos reglas tanto explícitas como implícitas en torno a los horarios y tipos de programas a los que diversos miembros de la familia pueden tener acceso; en torno al uso de NTC como la antena parabólica, la computadora, la registradora de llamadas telefónicas, etc.

Por ejemplo, en el caso de la televisión, su exposición se encuentra regulada por algunos factores físicos, como la disponibilidad de un espacio específico dentro de la casa, el número de aparatos de TV y la presencia de otras NTC en casa, y el espacio concreto en el que la TV se localiza. Pero, también hay otro tipo de reglas que tienen que ver con el ritmo de las actividades de la ida diaria, las responsabilidades dentro y fuera de casa, asi como la forma de concebir el tiempo de esparcimiento. En las familias estudiadas, se contaba con al menos dos aparatos de televisión a color, una de ellas con videograbadora y, en una de las familias se contaba con sistema restringido de televisión (Multivisión). Es muy común en este tipo de familias, contar con un cuarto de televisión, dejando el otro aparato para la recámara de los padres, en primer lugar y, en caso de contar con una tercera, ésta estaría situada en la recámara de los niños o en algún lugar específico para las empleadas domésticas (como la cocina). Ello permite a la familia poder ver simultáneamente una enorme variedad de programas a diverentes horarios.

En ambas familias resultó muy común encontrar a los niños menores de 15 años haciendo sus tareas escolares frente al televisor, comiendo o cenando, o aún guisando. Este tipo de interacción con la TV nos resulta familiar a los que vivimos en zonas urbanas. La edad es un factor fundamental que determina la cantidad de tiempo dedicada a ver programas. Los menores de 15 años ven en promedio de 2 a 3 horas diarias, ecogiendo dentro de la programación tanto caricaturas como telenovelas. En el caso de adolescentes, éstos seleccionan cuidadosamente las series televisivas o películas, tendiendo a una selección nocturna. Y en el caso de los adultos, sobre todo hombres, su exposición a la televisión se reduce a: escuchar algún noticiero (televisivo o radiofónico) mientras se preparan para salir al trabajo, y otro al regresar por la tarde. Las mujeres adultas señalaron no poder seleccionar los programas que "a ellas les gusta ver" ya que el control se 
encontraba generalmente en los hijos (al ver caricaturas o algún programa vespertino) o en los hombres al regresar del trabajo. Ellas en raras ocasiones pueden ver la televisión sin internupción y, una mencionó que "le encantaba poder rentar películas románticas para verlas por la mañana cuando sus hijos estan en la escuela."

Claramente existen reglas sobre el tiempo y tipo de programación que pueden seleccionar los menores, ya que se prioriza el tiempo dedicado al trabajo escolary a ciertos cursos extraescolares. Sin embargo, los niños señalan ver más TV de lo que los padres aceptan, y fue claro que ven programas que no estarían permitidos (tres señalaron ver telenovelas después de las 21:00 horas).

En cuanto se refiere a género, las mujeres adultas, en su papel de madres y ser "responsables" del trabajo de casa (aún en el caso de la que trabaja), en la mayoría de los casos, ven la televisión al tiempo de hacer o arreglar la comida, revisar la tarea, vestir a los hijos. Desde luego que la programación más popular para las mujeres, no importando la edad, son las telenovelas. Estas, al igual que en el estudio de Barrio (1994), encontramos que constituye una fuente importante de interacción y conversación que se realiza en la casa, la escuela, el trabajo o con los amigos. Comentan en torno a las temáticas, conductas, modas, etc. Esto es tan cotidiano en sus vidas que, afirman, prender la televisión en un canal, sin importar lo que éste les presenta.

A manera de contraste, a los hombres adultos, la televisión les "exige una mayor concentración" y selectividad de los programas. Ellos justifican su interacción con los medios como una "necesidad de buscar información" o "una forma importante de descanso". Resulta común para ellos emplear el control remoto y cambiar continuamente de canales hasta ubicar el programa que más llame la atención. Los hombres suelen programar de manera más consciente el tipo de programas que desean ver, a diferencia de las mujeres que "encienden" el televisor en un canal y ven lo que éste ofrece. Ellos suelen buscar la programación y los horarios (en diarios o en alguna otra publicación) prefiriendo los programas deportivos, noticieros y películas. Sin embargo, aunque en la observación se registró que comparten con la familia el ver las telenovelas después de las 21 horas, no aceptan abiertamente "elegirlas" y lo justifican por el hecho de ser "tiempo que pasan con la familia" no tanto porque sea un programa realmente interesante.

En los hijos menores, por ejemplo los adolescentes, no encontramos un patrón tan definido como en el caso de los mayores. Ellos buscan programas juveniles, indistintamente de su sexo, y les atraen todas las series de acción, aquéllos doblados al español considerados como "comedy" (El principe del rap, por ejemplo), y comparten con sus padres el interés por algunos noticieros. Ciertamente, las telenovelas son mucho más 
Globalización y medios de comunicación ¿Hacia ...

buscadas por las "jovencitas" que por los jóvenes, y, como sus padres, ellos no aceptan verlas.

Diferencias reales entre niños y niñas no pudieron encontrarse en cuanto a programación televisiva o música. Sin embargo, el uso de videojuetos es mucho más frecuente en los niños. No sólo juegan más tiempo, sino que en su interacción diaria con los amigos, forma parte importante en sus conversaciones. Esto mismo ha sido corroborado por otras investigaciones en la ciudad de $\mathrm{Puebla}^{8}$ en donde la variable sexo fue determinante en la variedad y tiempo dedicado a videojuegos. A pesar de la mercadotecnia que ha buscado atraer a las niñas con temáticas propias para ellas (incluyendo personajes femeninos de Walt Disney, por ejemplo), no logra cautivarlas. Reconocemos aquí, que sería necesario un estudio mucho más completo respecto a videojuegos y la manera en que ha cambiado la interacción y el juego en los niños.

En cuanto a las diferenciación de género y edad en la interacción con los medios resulta interesante encontrar la manera en que estas personas se relacionan con los medios masivos, al grado de formar parte de su rutina diaria. En función de la edad, los niños desempeñan una relación mucho más activa con la televisión o la radio, ya que juegan, hacen ruido, imitan algunas acciones transmitidas (por ejemplo, juegan con el coche o el avión de la pantalla). Mientras que los adultos toman una actitud mucho más relajada o concentrada frente a la televisión. A pesar de existir cierto control respecto de la programación y el tiempo que los menores ven la televisión, de hecho éstos tienen una enorme amplitud en la selección.

En lo concerniente a otros medios de comunicación, el radio y la grabadora forman parte de las vidas en estas familias. Los jóvenes adolescentes y adultos (hombres y mujeres) escuchan música grabada y disco compacto en varias ocasiones durante el día. Existe un aparato de música en algún lugar familiar (sala, comedor, por ejemplo), pero además encontramos otros en las recámaras, de los padres y de los hijos adolescentes. En la mañana se suelen escuchar los informativos radiofónicos y el resto del día se prefiere la música grabada. Solamente uno de los adolescentes señaló importante escuchar los programas de complacencias radiofónicas por las tardes. Este tipo de medios se vuelven "transparentes" en el sentido de no requerir demasiada concentración por parte de los

8 Jacobo Issa Villa (1992) El uso de videojuegos en las familias poblanas. Una primera aproximación. Tesis de licenciatura en Ciencias de la Comunicación. UDLA-P 
usuarios y de acompañar sus actividades diarias dentro de casa y en su traslado (en el coche).

La radio se enciende en algunos casos temprano, para escuchar las noticias o acompañar las labores del hogar. Sin embargo, en ambas familias, y sobre todo los jóvenes y adolescentes, señalaron preferir escuchar música grabada de su preferencia (baladas, rock, muchas veces en inglés).

La presencia de al menos un diario informativo y de dos a tres revistas mensuales en las familias resultó formar parte de su contacto con los medios. Sin embargo, aún los adultos no cuentan con un hábito de lectura ni frecuentan librerías o bibliotecas.

En relación con el conjunto de medios de comunicación encontramos una cierta coincidencia en las formas de regulación explícita o emplícita de su uso. Por ejemplo, en una familia no existe regulación del tiempo que se pasa frente al televisor o de los programas seleccionados por los niños. Esto mismo ocurre con videojuegos o aún con la renta de algunas películas. En la otra, por el contrario, aquélla en la que la madre trabaja, existe un horario y un mayor control sobre el tipo de programación y el tiempo. Eesta estructura se rtransfiere al uso de todo tipo de medios como es el uso de videojuegos, la renta de películas o aún el tiempo en que se escucha la música grabada. Por ejemplo, es común que la madre seleccione el tipo de programas que ven los niños y, al mismo tiempo, las Llamadas telefónicas soncontroladas a los hijos adolescentes; los padres eligen las películas y el tipo de material videográfico que suelen ver.

Por último, solamente en una familia encontramos una computadora personal, empleada básicamente por el padre y aún restringido a los hijos. En ningua de estas familias se emplea el fax o alguna otra forma de comunicación como podría ser el internet. El teléfono celular, de uso reciente, empleado por uno de los padres, pero como apoyo a su trabajo profesional. En la familias se cuenta con al menos una línea telefónica y de dos a tres extensiones (una de ellas inalámbricas) desempeña un papel importante en el tiempo dedicado a la intercomunicación.

Este acercamiento a la interacción entre la familia urbana y los medios masivos nos permiten dar cuenta de la profunda interdependencia que se establece entre éstos (Ball-Rockeach, 1989). Los medios pasan a formar parte de la vida diaria, de los proyectos, del conocimiento y apreciación de la realidad social en un contexto mucho más amplio -local, regional, nacional. Podríamos señalar, en principio, la enorme coincidencia entre las esquematizaciones propuestas por la programación mediática y aquélla de las familias urbanas y de nivel socioeconómico alto. Por ejemplo, resulta interesante que alguno de los jóvenes entrevistados, señaló "no encontrar ninguna diferencia" entre 
Globalización y medios de comunicación ¿Hacia ...

la temática y contexto familiar de un programa como "El Príncipe del rap" (familia norteamericana de negros de nivel socioeconómico alto) y la manera en que él mismo interactua con sus padres. La mayoría de los miembros de la familia no encuentran ningúna "discontinuidad" entre programas que representan la realidad mexicana y aquélos de la norteamericana. De alguna manera "se han acostumbrado" a estas programaciones y, al estar doblados al español, para ellos no constituyen una fuente importante de cuestionamiento de su realidad. En esta línea habría que profundizar mucho más la investigación en el análisis concreto de las represẻntaciones sociales propuestas por la programación y aquéllas de lo individuos receptores. Sin embargo, en este primer acercamiento, no encontramos contraste o contradicción alguna. Ello no sugiere, en ningún momento, que pretendamos hablar de una homogeneización de la audiencia como propondrían algunos autores, o de "masificación" y pérdida de una identidad diferenciada. Sin embargo, este primer acercamiento nos habla de una clara "adaptación" por parte de las familias urbanas a los códigos y tematizaciones propuestas por los medios, tan comunes en sus vidas, que han sido itegradas como parte misma de su proceso de "socialización." Sin embargo, veamos lo que sucede en el campo en una comunidad tradicional.

2. El ámbito rural. Durante los meses de Mayo a Septiembre realizamos el seguimiento etnográfico de dos familias en el pueblo de San Jerónimo Coyula, Atlixco $-4,500$ habitantes. Intencionalmente se buscó una familia extensa y otra nuclear con la finalidad de encontrar alguna diferencia importante en su interacción con los medios. Como podremos ver, existe un contraste importante en la forma en que éstas se relacionan con los medios, dependiendo fundamentalmente del "tiempo de esparcimiento" tan reducido con el que cuentan, debido a las innumerables obligaciones tanto en el hogar, la escuela o el trabajo de campo. Por otro lado, al tratarse de familias pobres, no cuentan con la diversidad ni con el número de aparatos receptores con que cuentan las familias urbanas descritas con anterioridad.

Cabe señalar que, los patrones de exposición e interacción a los medios no cambiaron de manera relevante por el hecho de tratarse de una familia extensa o nuclear, salvo en el hecho de que en la primera existe un mayor número y variedad de aparatos. Por ello, nos limitaremos a presentar los resultados preliminares de esta investigación en función de las variables de género y edad ya que éstas definen patrones perfectamente diferenciados. 
Los hombres adultos, trabajan fundamentalmente en el campo, cultivando la parcela familiar y, además como empleados en una granja cercana al pueblo. Su vida gira totalmente en torno al trabajo y su jornada. Descansan un día a la semana y sus horas y días de descanso los dedican a sus tareas agropecuarias. Este dato es fundamental para explicar su relación mínima con los medios masivos de comunicación. Sólo esporádicamente ven algún programa televisivo (deportivo, musical o película mexicana), y no acostumbran a leer ningún tipo de diario o revista. La radio es el medio más importante que les sirve de "compañôa" en sus actividades domésticas, pero no así en el campo.

Es interesante notar que su conocimiento de la vida pública nacional o regional es mínima. Si acaso conocen a algunos artistas o deportistas, pero, por ejemplo no pueden identificar más que el nombre del presidente o del gobernador del estado, no así de alguna otra figura política regional. Aún las noticias locales son transmitidas por medios interpersonales (reuniones del comité ejidal, de padres de familia o el sermón dominical). Los medios masivos, al ser en su mayoría repetidoras de canales nacionales o de las estaciones estatales (ubicadas en la ciudad de Puebla) no tocan la problemática local.

Lo anterior explica en gran parte su desinterés y aún "desconfianza" de los medios de comunicación, que hablan únicamente de cuestiones totalmente ajenas "al problema de la economía, o de los hijos que se vany no encuentran trabajo." Ambas familias cuentan 'al menos con un miembro que ha emigrado a los Estados Unidos en busca de oportunidades de trabajo y, aunque a su retorno éstos los proveen de algunos aparatos sofisticados de música o televisión, resulta importante resaltar que el tipo de programación que escuchan o ven corresponde a los llamados "códigos populares" y a los géneros agonísticos -lucha libre, box, juegos de futbol, entre otros. ${ }^{8}$

La radio permanece encendida prácticamente desde que amanece ( 5 a.m.) hasta que anochece ( $10 \mathrm{u} 11$ de la noche). Se escucha primordialmente música ranchera y romántica. $Y$ aunque han asistido al cine en contadas ocsiones durante su vida en la ciudad de Atlixco, ésta no es una actividad frecuente.

Por su parte las mujeres, desarrollan un sinnúmero de actividades domésticas y extradomésticas que ocupan la mayor parte de su día. En el caso de Doña Zenobia (43 años) afirma que "la tele no le gusta" y además "no tiene tiempo para el descanso". Aunque el aparato de TV se encuentra en la pieza donde están sus camas, son sus hijos menores los que la prenden sin que ella le preste atención. Afirma que, incluso las telenovelas "son

9 Consultar Gendreau M. y G. Giménez (1996) Op. Cit. 
programas tontos" ya que "hablan de gente que no es como nosotoros" y no se refieren al campo ni hablna "de lo caro que está todo." Afirma expresamente que lucha con sus hijas pequeñas para que no la vean, "pues sólo les llenan la cabeza de ideas..."

En este medio, se comprueba claramente que la edad desmpeña un papel fundamental en la integración de la televisión a la vida diaria. Son las hijas y lo snietos menores de 15 años los que declaran ver con mayor frecuencia la televisión. Las niñas en edad escolar acostumbran realizar sus tareas escolares frente al televisor por las tardes, pero no ven las caricaturas, sino más bien las telenovelas. Calixto, de 11 años, afirma que en realidad no le gusta ver la televisión. Prefiere jugar fútbol con sus amigos. De vez en cuando llega a ver algunos programas de caricaturas (por ej. Power Rangers) pero sus hermanas no le permitene cambiar el canal de las telenovelas. Es generalmente la hermana mayor (15 años) quien escoge no sólo el progrma televisivo, sino también el radiofónico o incluso el cassette de música que se escucha.

No obstante, en ambas familias, son las hijas adolescentes ( 12 y 15 años) las que más tiempo pasan cerca del televisor y la radio. De hecho son ellas las que aceptan elegir la programación y buscar todo tipo de melodramas. A pesar de tener fuertes obligaciones de trabajo doméstico, buscan la manera de combinar sus labores con la exposición a radio y televisión.

Aunque existen en el pueblo tres expendios con máquinas de vidojuegos, éstos no son frecuentados por los niños debido a su "alto precio" y a que no tienen mucho interés. Para los adolescentes y jóvenes, los pasatiempos favoritos son salir a las ciudades de Atlixco y Matamoros en días de plaza o ala feria de Cholula, asistir a las fiestas ("tocadas") y escuchar música. Compran cassettes regrabados ("piratas") a bajo precio ( $\$ 10.00$ cada uno) en el mercado de Atlixco.

Es clara, en este medio, la enorme importancia que tienen la radio y la música grabada sobre la televisión, ya que las primeras son compatibles con sus actividades cotidianas y no requieren atención como la última. Contrariamente a lo que sucede con el medio urbano, la televisión o los programas televisivos no son fuente de conversación frecuente entre los miembros de la familiay, como ya lo mencionamos, las noticias locales nos son trasmitidas por la radio u otro medio, por lo que la fuente ordinaria de información implican la comunicación interpersonal.

En el medio rural encontramos con enorme claridad una enorme "resistencia" a las esquematizaciones televisivas y radiofónicas urbanas. No sólo no les "interesa" la programación, porque "no habla de los suyo", sino que, además desconfían de ella: "sólo les llena la cabeza de ideas..." "no tienen tiempo que perder" La selección y preferencia 
de música ranchera y romántica, desde luego en español y el tipo de programas que "corresponden" de alguna manera a sus representaciones sociales de la realidad campesina son un hecho. Aún, los medios no son indispensables para la realización de sus actividades y proyectos, no les permiten "conocer" aspectos del ámbito regional o nacional, y la información necesria y crucial para su vida en la localidad, la obtienen mediante formas orales tradicionales: ferias, fiestas, sermones, reuniones.

Sin embargo, no podemos dejar pasar por algo, la mayor interacción de los niños y jóvenes con los medios. El proceso de socialización temprana incluye una presencia continua de medios, y opciones cada vez más diferenciadas. Sin duda que la migración (tanto nacional como internacional) está generando un mayor contacto con la "modemidad" urbana, lo que permitirá incluir en sus esquematizaciones elementos propios de aquel contexto e integrarlos con mayor rapidez a través de las programaciones con códigos urbanos que ofrece la televisión.

\section{A modo de conclusión}

No es posible todavía hablar de conclusiones definitivas, ya que, el proceso de interrelación familiar con los medios implica, además de la aproximación etnográfica, la consideración de un plazo mayor. Sin embargo, al comparar tanto el ámbito urbano con el rural, como los resultados arrojados por una técnica descriptiva como es la aplicación de cuestionarios, frente a la rica y variaca información proporcionada por la aproximación etnográfica, podemos empezar a descubrir un paisaje mucho más rico en matices detrás del frío concepto "exposición a los medios."

Nos gustaría proponer las siguientes reflexiones de manera que permitan guiar y replantear la investigación-en-proceso, abriendo la discusión en lugar de cerrarla.

1. Al comparar los resultados arrojados por las encuestas en el ámbito tanto urbano como rural, se encuentran muy pocas diferencias en cuanto a accesibilidad. La televisión y el radio se encuentran presentes universalmente en las familias del campo y la ciudad. Sin embargo, este primer acercamiento debe ser matizado por el hecho de que, en las familias de nivel socioeconómico elevado, se cuenta con un mayor número, variedad y sofisticación de aparatos. En las familias campesinas no encontramos siquiera teléfono, mucho menos antena parabólica o computadora. Es entonces que podriamos hablar con Shiller (1993) de una nueva forma de estratificación social generada a partir del acceso/no acceso 
Globalización y medios de comunicación ¿Hacia ...

a las Nuevas Tecnologías de Comunicación, restringidas aún a las familias con elevados ingresos.

2. Es interesante notar, también la "omnipresencia" de los medios auditivos (radio/grabadora) que permiten acompañar todo tipo de actividades domésticas, de trabajo y de desplazamiento de la población. Claro que aquí la diferencia se encontraría básicamente en el tipo o género musical o programa que se escucha. En las familias rurales, únicamente se escucha música acorde a sus códigos populares campesinos: música ranchera y romántica. Aunque algunos jóvenes señalan escuchar "música grupera" siempre es en español.

A diferencia de ello, en las zonas urbanas y en las familias de altos recursos, la radio es superada por el empleo de música grabada (cassette y disco compacto) y los géneros son sumamente variados, pasando desde la música orquestada hasta el rock metálico y combinando tanto la balada en español como la música en inglés.

3. Cuando empezamos a entrar en profundidad y a descubrir lo que se encuentra "detrás" de el hecho de "ver" televisión, podemos percatarnos de la enorme familiaridad con la que las familias urbanas comparten sus actividades con este medio. Las programaciones bastante bien definidas por el sexo y la edad. Los hombres mayores, noticieros; las mujeres (casi de cualquier edad) las telenovelas y los jóvenes y niños programas infantiles, cómicos y de aventuras (incluyendo aquéllos norteamericanos doblados al español).

En el campo, los únicos géneros que podríamos considerar "populares" son precisamente los agonísticos -lucha libre, box, fútbol-y, las universalmente vistas telenovelas. Desde luego que, las películas mexicanas, correspondientes a la "Epoca de Oro" son bastante bien aceptadas.

4. Las Nuevas Tecnología de Comunicación ofrecen, por otro lado, una serie de alternativas de entretenimiento importantes en las zonas urbanas. Es interesante ver cómo los videojuegos están cambiando los patrones de interacción y juego entre niños. Asímismo, el uso de la videograbadora ha permitido desplazar casi por completo la asistencia a salas de cine y ha establecido, por otro lado, una nueva forma de compartir el tiempo en familia, ya que se "eligen el tiempo y el material" a ser visto con anticipación. Lo mismo podríamos decir de algunos programas transmitidos por antena parabólica o a través de la televisión restringida. 
5. Uno de los elementos más ricos a ser analizados que arroja la presente investigación es el hecho de que, contrariamente a lo esperado, muchos de los programas propuestos por los medios de comunicación, no son uniformemente aceptados e integrados en la población. Es claro, aunque merece una mayor profundización en su estudio y análisis, que las representaciones culturales del medio nural, al no coincidir con aquéllas propuestas por los medios, impiden que estas personas "decodifiquen" adecuadamente el mensaje que se les propone. Y por ello, prefieren evitarlo por encontrarlo carente de "sentido."

Si bien los jóvenes empiezan a "abrir" y compartir algunas de sus representaciones hacia los materiales propuestos por los medios, aún no estamos en condiciones de definir si ésto conlleva a un cambio profundo en la propia cultura tradicional, o si se trata de una mera adaptación a nuevos códigos, pero integrados en una matriz cultural fundamentalmente rural. Este es el objeto de la investigación mayor en la que se inserta el presente trabajo.

6. Por último, conviene señalar que, desde nuestro punto de vista, el 'efecto' de los medios masivos en contextos socioculturales tan diversos no ha sido el de homogeneizar o masificar cierta cultura mediática. No podemos aceptar la tesis de la aldea global, sino, por el contrario, afirmamos la presencia de múltiples aldeas, si bien en una situación de dominacióny de relación desigual -en el sentido de que no concebimos cómo los códigos rurales podrían dominar la producción mediática controlada por los grandes consorcioscon respecto de aquéllas sociedades centrales, industrializadas y capitalistas.

Es claro que la integración económica, la llamada "globalización" conlleva a una mayor interacción comercial y financiera, pero no implica necesariamente ni la integración ni la homogeneización de las culturas "dominadas" o "periféricas". Sobre ésto, hay mucho que seguir indagando.

\section{Bibliografía}

ANG, Ien (1991). Desperately seeking the audience. London: Routledge.

BALL-ROKEACH, Sandra \& Melvin L., DeFleur(1988). Theories of Mass Communication.

(5th. ed.) New York: Longman.

BAUSINGER, H. (1984). "Media Technology and everyday life". Media, Culture and Society, 6 (4). 
Globalización y medios de comunicación ¿Hacia ...

Blumer, Herbert (1948). "Public Opinion and Public Polling". American Sociological Review, 13 (5) pp.542-554.

BOURDIEU, Pierre (1972). "Public Opinion does not exist". InInternational General, New York, 1, pp.124-130.

(1972). Esquisse d'une théorie de la pratique, París, Droz.

(1980). Le sens pratique, París, De Minuit.

(1980). Questions de Sociologie, París, De Minuit.

CanToR \& Cantor (1986). Audience Composition and Television Content. In: Ball-Rokeach, S. \& Cantor, M. Media Audience and Social Structure. Beverly Hills, Sage, p.215-225.

DEARING, James W. (1989). "Setting the Polling Agenda for the Issue of AIDs", Public Opinion Quarterly, 53, pp.309-329.

FISKE, J. (1986). "Television: polysemy and popularity", Critical Studies in Mass Communication, 3 .

Foss AERT, Robert (1978). La Société. Les appaeils, tomo III, París, Ed. Du Seuil. (1983). La Société. Les Structures idéologiques, París, Ed. Du Seuil.

Fouler, R.; Hodge, B.; Gunther, K. \& Trew,T. (1979). Language and control, London, Routledge \& Kegan.

García CANClini, Néstor (1982). Las Culturas populares en el Capitalismo, México, Nueva Imagen.

Gendreau, M. (1993). Perfil de Audiencias en la Ciudad de Puebla. Reporte de investigación. Universidad de las Américas-Puebla.

Giddens, Anthony (1976). New Rules of Sociological Method: A Positive Critique or Interpretative Sociologies, London, Hutchinson. (1979). Central problems in Sociological Theory, London, Hutchinson.

GIMÉNEZ MONTIEL, Gilberto (1987). La teoría y el análisis de la cultura, Programa Nacional de Formación de Profesores Universitarios en Ciencias Sociales. México, SEP, Universidad de Guadalajara, COMECSO.

(1993). "Cambios de identidad y cambios de profesión religiosa", en Bonfil Batall, G. (Coord.) Nuevas identidades culturales en México, México, CNCA Seminario de Estudios de la Cultura, pp.23-54.

GiNER, S. (1976). Mass Society, London, Martin Robertson.

GómEZ-MONT, Carmen (1992). El desafio de los nuevos medios de comunicación en México, México, AMIC-Diana. 
GoNZÁLFZ, Jorge A. (1988). "La cofradía de las emociones (in)terminables", Estudios sobre las Culturas Contemporáneas, II (4/5), Universidad de Colima.

GRAMSCI, Antonio (1975). Los intelectuales y la organización de la cultura, México, Juan Pablos Ed.

GRIZE, Jean-Blaise (1990). Logique et langage, París, Ophrys.

HaLl, Stuart (1980). Encoding/Decoding. Hall, Hobson, Lowe, Willis (eds.) Culture, Media, Language, London, Hutchinson.

HODGE, Robert (1979). Language as Ideology, London, Routledge \& Kegan.

Hodge, R. \& Kress, G. (1988). Social Semiotics, Cambridge, Polity Press.

HodGE, R. \& Tripp, D. (1986). Children and Television: A Semiotic Approach, Cambridge, Polity Press.

JENSEN, Klaus Bruhn (1992). "La política del multisignificado. Noticias en la televisión, conciencia cotidiana y acción política", en Orozco, G. (Comp.) Hablan los televidentes. Estudios de recepción en varios países, México, UIA. (Cuadernos de Comunicación y Prácticas Sociales No.4).

LOMNITZ-ADLER, C. (1995). Las salidas del laberinto. Cultura e ideologia en el espacio nacional mexicano, México, Joaquín Mortiz-Planeta.

LuENGo gonZalez, Enrique (1982). Problemas metodológicos de la sociología contemporánea, Taller de Investigación para la Comunicación Masiva (TICOM), México, Universidad Autónoma Metropolitana.

LuLL, James (ed.) (1988). World families watch television, London, Sage.

MARTín BARBERO, Jesús (1987). De los medios a las mediaciones: Comunicación Cultura y Hegemonía, México, G.Gili.

MCLuhan, Marshall and Quentin, Fiore (1989). War an Peace in the Global Village, New York, Touchstone.

MCQUAIL, Dennis (1992). Introducción a la teoria de la comunicación de masas, México, Paidós Comunicación.

MoWLANA, H. \& L. Wilson (1990). The passing of Modernity, New York, Longman.

MEYROWITZ, Joshua (1985). No Sense of Place: The Impact of Electronic Media on Social Behavior, New York, Oxford University Press.

MichaUd, G. (dir.) (1978). Identités collectives et relations interculturelles, Bruselas, Complexe.

MORLEY, David (1986). Family television: Cultural power and domestic leisure, London, Comedia/Routledge.

MORLEY, David (1992). Television, audiences and cultural studies, London, Routledge. 
Globalización y medios de comunicación ¿Hacia ...

Moscovici, S. (1967). "Communications processes and the properties of language", en L. Berkowitz (ed.) Advances in experimental social psychology, New York, Academic Press, pp.225-270.

(1989). "Des représentationes collectives aux représentations sociales", en D. Jodelet (ed.) Les Représentations Sociales, París, PUF, pp.62-86.

MURDOCK, G. (1989). "Critical Inquiry and Audience Activity", in: B. Dervin (et.al.)(eds.) Rethinking Communication, vol.2, Newbury Park and London, Sage. Orozco GÓMEZ, Guillermo (1991). Recepción televisiva. Tres aproximaciones y una razón para su estudio, México, UIA (Cuadernos de Comunicación y Prácticas Sociales No.2).

(Comp.) (1992). Hablan los televidentes. Estudios de recepción en varios países, México, uIA (Cuadernos de Comunicación y Prácticas Sociales No. 4).

(Coord) (1994). Televidencia. Perspectivas para el análisis de los procesos

de recepción televisiva, México, UIA (Cuadernos de Comunicación y Prácticas Sociales No. 6).

RICOEUR, P. (1978). The Rule of Methaphor: Multi-disciplinary Studies of the Creation of Meaning in Language, (tmas. Costello), London, Routledge \& Kegan.

SAID, Eduard (1993). Culture and Imperialism, New York, Vintage Books.

SHANNON, C.E. and W., Weaver (1985). Teoria matemática de la comunicación. (1949)...

SHILLER, Herbert I. (1993). Cultura, S.A. La apropiación corporativa de la expresión pública, (Trad. E. Carballo), Guadalajara, CEIC, UdeG.

SHINAR, D.; J. Olarhooen \& C. Yalden (1990). Dismembering and Re-membering: An Improved Conceptual Framework for the Analysis of Communication and Social Change, Montreal, Concordia University.

Swingewood, R. (1977). The Myth of Mass Culture, London, Macmillan.

THOMPSON, John B. (1990). Ideology and Modern Culture. Critical Social Theory in the Era of Mass Communication, Stanford, Ca., Stanford Universsity Press.

TURNER, Graeme (1990). British Cultural Studies, Boston, Unwin Hyman (Media and Popular Culture:7). 